\title{
A Vision for Stroke Rehabilitation Transformation in Ontario
}

Can. J. Neurol. Sci. 2011; 38: 806-807

Matthew J. Meyer and colleagues have written a thoughtprovoking article on the challenges faced by Ontario's stroke rehabilitation system. ${ }^{1}$ They mirror a 2010 Canadian Medical Association (CMA) document entitled Health Care Transformation in Canada: Change that Works, Care that Lasts ${ }^{2}$ and use it to highlight the complicated system of post-stroke rehabilitation "where involvement of multidisciplinary teams that include physicians, therapists, nurses, social workers and many other professionals is required. In order to be effective, these professional services must be available from the time of acute discharge through to community reintegration, posing tremendous challenges."

The last author of the article is Robert Teasell, a specialist in physical medicine and rehabilitation (physiatrist) at the University of Western Ontario. He has spent significant time over the past years discussing and writing about what the success of stroke rehabilitation depends on and how numerous studies, particularly European ones, ${ }^{3,4}$ have documented that stroke rehabilitation lowers rates of stroke-related morbidity and mortality. ${ }^{5}$ Some of the concepts that he promotes regarding stroke treatment challenge long-held beliefs. His ideas are stimulating but may be unnerving to those comfortable with the status quo.

The article focuses on how applying the principles endorsed in the CMA document can help the Ontario stroke rehabilitation system become both patient-focused and sustainable. The authors note that too few stroke survivors discharged from acute care facilities are being admitted to inpatient rehabilitation across the province. Gaps in accessibility are even more evident among patients discharged to the community, with fairly minimal access to occupational therapy, physical therapy, and speech and language pathology therapy. The authors rightly point out that "when patients do not have access to the level of care they require, they are often left to pay for such services outof-pocket." This is certainly what I see daily in my practice as a stroke rehabilitation specialist.

Some of the controversial content of the paper concerns the numerous stakeholders in stroke rehabilitation, who "have different motivations for action." For example, rehabilitation clinicians develop personal relationships with their patients and want to maximize their recovery. Clinicians do not necessarily have to account for the efficiency or cost of their care, and active rehabilitation is not prioritized over non-therapeutic activities. This creates an environment that is less productive.

The authors note that lack of meaningful measures for program evaluation leads programs to focus "only on the patients they admit and neglects patients who require rehabilitation but cannot access services." This issue is not restricted to stroke rehabilitation. The overall program performance of any neurology or internal medicine service is a victim of similar issues. Has anyone ever counted how many imaging studies of the brain get ordered during an acute care inpatient stroke stay? The number of unnecessary studies may translate into additional months of waiting for outpatients requiring imaging. The authors state that the Ministry of Health and Long-Term Care is unable to adequately assess rehabilitation efficiency and that program administrators have little incentive to improve access to stroke rehabilitation programs. Although these observations may be perceived as hurtful to some program administrators, they are accurate and merit further discussion.

The authors propose a vision for transformation to a patientfocused system that encompasses principles such as addressing the needs of all stroke survivors, including those who are not able to access the care they need, and a "patient-first" approach to treatment provision. This would be achieved in part by developing and collecting a composite indicator reflecting both patient outcomes and population-level efficiency. The first step would be to compile information regarding the proportion and characteristics of patients recovering from stroke in all regions who are not admitted to rehabilitation programs. This is certainly required. Only then will we be able to create specific models to ensure better accessibility for all stroke survivors. The authors' recommendation for appropriate peer-group comparisons is valid, and the current system is inadequate to carry out such comparisons.

Particularly controversial is the proposal that, once benchmarks have been established, the dose and duration of rehabilitation therapy can be "treated in the same way that they are in pharmaceutical administration." The concept of "seven day a week" stroke rehabilitation is one that most definitely must be discussed. The efficacy of such a model and whether it fits within Canadian work standards and capabilities need to be examined. Questions such as "Can we afford not to utilize weekend hours for stroke rehabilitation therapies?" versus "Can the (often aged) person recovering from a stroke tolerate the extra weekend rehabilitation demands?" need to be laid on the table.

The authors' vision for stroke rehabilitation transformation makes much sense. The core value of the paper lies in the concept that we need to change aspects of the stroke rehabilitation care provided in Canada. Many of the principles apply to acute care as well. This change will not happen within individual institutions but, rather, will need a government or multiorganizational approach to create the necessary structures and incentives to make it happen. The authors note that the CMA recommends shifting public reporting from "shame and blame" to quality improvement, with rewards provided for efficient, patient-focused care. This is a very hopeful message. We need more visionary articles like this one so that patients can truly benefit from a continuum of care that starts with stroke prevention, moves to acute care, then rehabilitation, and ends up back in the community, where rehabilitation continues for as long as needed. 


\section{ACKNOWLEDGEMENTS}

The author thanks Gloria Baker and Crystal MacFarlane for editing the manuscript.

\section{REFERENCES}

1. Meyer MJ, Meyer JP, Foley N, et al. Stroke rehabilitation in Ontario: an opportunity for health care transformation. Can J Neurol Sci. 2011;38(6):810-14

2. Canadian Medical Association. Health care transformation in Canada: change that works, care that lasts. Ottawa: The Association; 2010 .
3. Rønning OM, Guldvog B. Stroke unit versus general medical wards, II: neurological deficits and activities of daily living: a quasi-randomized controlled trial. Stroke. 1998;29(3):586-90.

4. Rønning OM, Guldvog B. Outcome of subacute stroke rehabilitation: a randomized controlled trial. Stroke. 1998;29(4): 779-84.

5. Foley N, Teasell R, Bhogal S, Speechley M. The efficacy of stroke rehabilitation. Evidence-based review of stroke rehabilitation. 13th ed. (cited $2011 \mathrm{Jul} 7$ ). Available from: http://ebrsr.com/ uploads/Module-5_efficacy.pdf. 